\title{
Estímulo à criatividade por professores de Matemática e motivação do aluno
}

\author{
Alessandra Barbosa Nunes Otaviano \\ Eunice Maria Lima Soriano de Alencar \\ Cláudia Cristina Fukuda
}

\begin{abstract}
Resumo
O estudo investigou a percepção de alunos do Ensino Médio quanto à utilização, por seu professor de Matemática, de práticas docentes favoráveis ao desenvolvimento da criatividade e motivação em Matemática. Participaram do estudo 396 alunos, os quais responderam ao Inventário de Práticas Docentes para a Criatividade e à Escala de Motivação em Matemática. Diferenças significativas foram observadas entre alunos de escola pública e particular na percepção das práticas docentes promotoras da criatividade, utilizadas por seu professor, e em motivação em Matemática, a favor dos alunos da escola particular. Observou-se ainda relação significativa entre a percepção dos alunos quanto ao uso de estratégias em sala de aula para desenvolver a criatividade por seu professor de Matemática e motivação do aluno em Matemática, entre motivação em Matemática e rendimento acadêmico nessa disciplina e entre a percepção pelo aluno de práticas pedagógicas para a criatividade e seu rendimento em Matemática.
\end{abstract}

Palavras-chave: Criatividade, motivação, matemática.

\section{Stimulating creativity of teachers of mathematics and student motivation}

\begin{abstract}
The study investigated high school students' perception about pedagogical practices used by their Mathematics teacher to promote the development of creativity and students` motivation in Mathematics. The participants were 396 students who completed the Inventory of Teaching Practices for Creativity and the Scale of Motivation in Mathematics. Significant differences were observed between public and private school students in their perception of pedagogical practices implemented by the Mathematics teacher to develop creativity and in their motivation in Mathematics, favoring the private school students. The results also indicated a relationship between students' perception of the use of strategies to develop creativity in the classroom by their Mathematics teacher and motivation in Mathematics, between motivation in Mathematics and academic achievement, and between student's perception of teaching practices for creativity and academic achievement in Mathematics.
\end{abstract}

Keywords: Creativity, motivation, teacher, Mathematics.

\section{Estímulo a la creatividad por profesores de Matemática y motivación del alumno}

\section{Resumen}

El estudio, realizado con alumnos de Enseñanza Secundaria, investigó la percepción de prácticas docentes favorables al desarrollo de la creatividad y motivación en Matemática utilizadas por su profesor de Matemática. Participaron del estudio 396 alumnos, que respondieron al Inventario de Prácticas Docentes para la Creatividad y a la Escala de Motivación en Matemática. Se observaron diferencias significativas entre alumnos de escuela pública y particular en la percepción de las prácticas docentes promotoras de creatividad utilizadas por su profesor. En motivación en Matemática las diferencias fueron a favor de los alumnos de la escuela particular. Además, se observó relación significativa entre la percepción de los alumnos sobre el uso de estrategias en clase para desarrollar la creatividad por su profesor de Matemática y la motivación del alumno en Matemática, entre motivación en Matemática y rendimiento académico en ese curso y entre la percepción por parte del alumno de prácticas pedagógicas para la creatividad y su rendimiento en Matemática.

Palabras Clave: Creatividad, motivación, Matemática. 


\section{Introdução}

Temida por muitos por ser uma disciplina usualmente definida como "difícil" e que mais "reprova", o ensino da Matemática, em muitas escolas, vale-se da tríade "ler, escrever e contar" (Silveira, 2002). Porém, Zaslavsky (2009) defende que "a Matemática é para todos", ressaltando que, quando são propostas ao aluno atividades desafiadoras, a Matemática pode se tornar uma fonte de muita alegria e satisfação. Para que o aluno se envolva com o saber, é necessário desenvolver estratégias que multipliquem as articulações internas entre os diferentes temas da Matemática, as várias maneiras de representar o conhecimento e entre o saber escolar e os conhecimentos do cotidiano. A valorização de procedimentos de ensino mais significativos requer a superação de práticas reprodutivas, substituindo-as por dinâmicas que ajudem o aluno a desenvolver sua criatividade (Pais, 2006).

Em sala de aula, os efeitos imediatos da motivação do aluno consistem em se envolver ativamente nas tarefas relacionadas ao processo de aprendizagem, o que implica ter sido escolhido esse curso de ação entre outros possíveis e ao seu alcance. Quando se pretende investir em uma aprendizagem eficaz, é fundamental levantar possíveis fatores que possam influenciar positivamente essa aprendizagem, entre eles o interesse pelo conteúdo e a motivação do aluno (Bzuneck, 2004, 2010). Gontijo (2007), no que diz respeito à Matemática, destaca que os educadores devem estar atentos às experiências que os alunos já vivenciaram, identificando fatores positivos ou negativos em relação a essa disciplina. Deve-se fazer uma análise do currículo, a fim de verificar se este privilegia os processos criativos ou apenas a memorização e, também, investir na formação dos professores para que possam desenvolver a sua criatividade e estimular o desenvolvimento da criatividade discente.

Percebe-se que, nos diferentes níveis de ensino, professores se queixam de alunos desmotivados (Tapia, 2003; Tapia \& Fita, 2006). A preocupação dos docentes no contexto escolar, segundo Bzuneck (2004), pode ser traduzida nas seguintes questões: por que alguns alunos completam as atividades, apesar do enorme grau de dificuldade, enquanto outros desistem no primeiro obstáculo? Será que a motivação é um dos elementos que influenciam o comportamento do aluno em sala de aula? O rendimento acadêmico tem influência na motivação do aluno?

Em muitas escolas, percebe-se que é atribuída ao professor a tarefa de mero transmissor de conhecimentos (Libâneo, 1994). Para Pais (2006), a valorização de estratégias de ensino mais significativas requer a superação de práticas reprodutivas por dinâmicas através das quais o aluno possa se expressar criativamente, pois é cada vez mais necessário desenvolver a criatividade discente com vista a preparar o aluno para enfrentar os desafios contemporâneos. Para Cunha (2006), os professores devem tornar as aulas mais atraentes, estimular a participação do aluno, in- duzir a crítica, a curiosidade e a pesquisa, buscando formas inovadoras de desenvolver a aula.

Nota-se que vários autores, como Alencar (2002, 2007; Alencar \& Fleith, 2009), Fleith (2007), Lubart (2007), Martínez (2002, 2006) e Wechsler (1998), têm apontado fatores que influenciam o desenvolvimento e expressão da criatividade no contexto educacional e propõem que, para se obter uma visão abrangente do desenvolvimento da criatividade nesse contexto, é essencial considerar, entre outros aspectos, o clima em sala de aula, devendo ser o professor receptivo a novas ideias. Nesse sentido, Alencar e Fleith (2009) sugerem diversas estratégias que o professor poderá utilizar para facilitar o desenvolvimento do potencial criativo do aluno, como permitir ao aluno formular questões, elaborar e testar hipóteses; dar tempo ao aluno para pensar e desenvolver as suas ideias; propiciar ambiente de respeito e estimular a habilidade discente de explorar consequências para acontecimentos imaginários.

Em Matemática, os professores devem buscar tópicos relacionados com as situações vivenciadas no dia a dia e incentivar os alunos a desenvolverem seus próprios métodos de resolução de problemas. Sequera Guerra (2006) ressalta que, para fomentar a criatividade em Matemática, é necessário que: a) o professor promova a motivação, curiosidade, autoconfiança, humor e flexibilidade discentes; b) favoreça o desenvolvimento de habilidades importantes, como aprender a visualizar um problema de distintos ângulos, inventar suas próprias técnicas de resolução de problemas, além de discutir e definir metas; c) os problemas propostos sejam instigantes e conectados com as experiências de vida dos estudantes. Por outro lado, D’Ambrósio (1989) dá como sugestões ao professor: instigar o aluno a construir conceitos matemáticos por meio de situações que estimulem a sua curiosidade; estimular o aluno com problemas de naturezas diferentes; interpretar o fenômeno matemático e incentivar o aluno a explicá-lo a partir de sua concepção da Matemática; envolver o aluno no "fazer" matemático, no sentido de criar hipóteses e investigá-las a partir da situação problema proposta.

Para Guimarães (2004), a determinação do aluno para cumprir uma atividade escolar pode ocorrer quando: a) percebe razões significativas para tal, ou seja, quando tem a atenção voltada para a compreensão do conteúdo de uma atividade que pode melhorar ou levá-lo a obter novos conhecimentos e habilidades; b) o significado daquele conteúdo está relacionado a interesses pessoais; e c) a proposta de atividade é definida em termos de metas específicas e de curto prazo, favorecendo a percepção de que, com certo grau de esforço, sua conclusão é possível.

Mas, para mudar o conceito que o aluno faz quanto à Matemática, muitas práticas pedagógicas utilizadas ainda hoje devem ser revistas, como as aulas expositivas em que o professor passa para a lousa aquilo que ele julga importante, o aluno copia e, em seguida, faz exercícios de aplicação que, em geral, são repetições de um modelo apresentado pelo professor. Assim, os alunos passam a acreditar que a aprendizagem em Matemática se dá por meio de um acúmu- 
lo de fórmulas e algoritmos, e que a Matemática é um corpo de conceitos verdadeiros e estáticos, sobre os quais não se pode duvidar ou questionar (D’Ambrósio, 1989).

Distintos estudiosos, como Alencar e Fleith (2009), Fleith e Alencar (2010), La Torre (2005), Lubart (2007), Kauart e Muniz (2008) e Wechsler (1998), associam a criatividade à motivação, especialmente a de caráter intrínseco. Ademais, sinalizam que práticas docentes promotoras da criatividade contribuem também para mobilizar o interesse e motivação do aluno no contexto escolar. Entretanto, observa-se carência de estudos empíricos a respeito do impacto de procedimentos pedagógicos facilitadores da criatividade na motivação do aluno, em especial no que diz respeito a práticas docentes implementadas pelo professor de Matemática e a motivação de seus alunos. Dada a relevância do tema e com vistas a contribuir para a literatura sobre estratégias de ensino para o desenvolvimento da criatividade e motivação do aluno, desenvolveu-se o presente estudo. O mesmo teve como objetivos investigar diferenças entre estudantes de escola pública e particular e do gênero masculino e feminino em sua percepção quanto a estratégias utilizadas por seus professores de Matemática em sala de aula para desenvolver a criatividade discente e em sua motivação em Matemática; bem como investigar a relação entre percepção dos alunos quanto ao uso de práticas pedagógicas pelo professor de Matemática para desenvolver a criatividade e motivação em Matemática, entre motivação em Matemática e rendimento acadêmico nesta disciplina e entre a percepção pelo aluno de práticas pedagógicas para a criatividade e seu rendimento em Matemática.

\section{Método}

\section{Participantes}

Participaram deste estudo 396 alunos da $2^{a}$ série do Ensino Médio de duas escolas (uma escola pública e uma particular) localizadas no Distrito Federal. Duzentos e vinte e um $(55,8 \%)$ respondentes eram do gênero feminino e 175 (44,2\%), do gênero masculino. A média de idade dos participantes foi de 16,01 , variando de 14 a 19 anos. Entre os participantes, $215(54,3 \%)$ eram alunos da escola particular e $181(45,7 \%)$ da escola pública. Não foi constatada nenhuma diferença significativa entre idade e gênero na amostra quando considerada separadamente por tipo de escola.

\section{Instrumentos}

Utilizou-se na coleta de dados os seguintes instrumentos:

1. Inventário de Práticas Docentes para a Criatividade, construído por Alencar e Fleith (2004) e validado em uma amostra de estudantes da Educação Superior. É composto por 37 itens a serem respondidos em uma escala de cinco pontos, variando de discordo totalmente (1) a concordo totalmente (5). Avalia os fatores "Incentivo a Novas Ideias"; "Clima para Expressão de Ideias"; "Avaliação e Metodologia de Ensino"; e "Interesse pela Aprendizagem do Aluno". Uma análise dos itens deste instrumento indicou que o mesmo seria também adequado para avaliar a percepção do estudante do Ensino Médio quanto às práticas docentes utilizadas por seu professor de Matemática.

2. Escala de Motivação em Matemática, construída por Gontijo (2007), composta por 28 itens, que são respondidos em uma escala de cinco pontos, variando de nunca (1) a sempre (5). Avalia os seguintes fatores: "Satisfação em Matemática"; "Jogos e Desafios"; "Resolução de Problemas"; "Aplicações no Cotidiano"; "Hábitos de Estudo"; e "Interações na Aula de Matemática".

3. Diário de Classe das turmas pesquisadas, no qual são registradas as notas alcançadas em cada bimestre em Matemática.

\section{Procedimentos}

Inicialmente foi agendado um encontro com os coordenadores pedagógicos das duas instituições de ensino para a apresentação dos objetivos da pesquisa e dos cuidados éticos que seriam tomados no decorrer da coleta de dados, bem como para solicitar sua autorização para a realização do estudo. Após a anuência dos coordenadores, o professor de Matemática de cada instituição foi contatado, informando-lhe sobre a pesquisa e identificando o horário mais conveniente de se aplicar os instrumentos. Foi assegurado o caráter confidencial dos dados e a não identificação dos participantes. Os objetivos do estudo foram devidamente explicados para os alunos, os quais também foram informados de que poderiam participar ou não da pesquisa. Antes de se iniciar a coleta de dados, todos os participantes leram e assinaram o termo de "Consentimento Livre e Esclarecido". Dez alunos da rede pública se recusaram a responder o questionário. Os instrumentos da pesquisa foram aplicados coletivamente em sala de aula, pela primeira autora. Os participantes não expressaram dificuldades na compreensão dos itens do questionário.

\section{Resultados}

\section{Influência de gênero e tipo de escola nos fatores de criatividade e motivação em Matemática}

Inicialmente, procedeu-se à análise exploratória dos dados separadamente por gênero e tipo de escola para cada 
fator de criatividade e motivação. Verificou-se a existência de outliers univariados pela análise do escore $z$, tendo sido encontrados três casos com escore z maior que 3,29 (Tabachnick \& Fidel, 1996). A análise da distância de Mahalanobis demonstrou a inexistência de outliers multivariados. Dois dos outliers univariados ocorreram no fator 2 da escala de motivação e um no fator 4 do inventário de criatividade, tendo sido tais casos excluídos das análises. Pela análise da assimetria e curtose, pôde-se verificar que houve apenas pequenos desvios da normalidade, sendo 0,85 o maior valor de assimetria encontrado e 1,45 o maior valor de curtose. Considerando a possibilidade do aumento da probabilidade de ocorrência do erro Tipo I, visto que a suposição de homogeneidade das variâncias não pôde ser garantida para todas as variáveis, decidiu-se utilizar alfa de 0,025 (Tabachnick \& Fidel, 1996).

Os resultados obtidos através da Análise de Variância Multivariada, tomando como variável dependente os

Tabela 1. Média, desvio padrão, valor F e $p$ nos fatores do Inventário de Práticas Docentes para a Criatividade e da Escala de Motivação em Matemática por tipo de escola.

\begin{tabular}{ccccc}
\hline $\begin{array}{c}\text { Variável } \\
\text { dependente }\end{array}$ & $\begin{array}{c}\text { Tipo de } \\
\text { escola }\end{array}$ & Média (DP) & $\begin{array}{c}\mathbf{F}(\mathbf{1}, \\
\mathbf{3 9 3})\end{array}$ & $\mathbf{p}<$ \\
\hline Fator 1c & 1 & $3,31(0,68)$ & 90,62 & 0,001 \\
& 2 & $3,84(0,460$ & & \\
Fator 2c & 1 & $3,19(0,65)$ & 121,10 & 0,001 \\
& 2 & $3,78(0,39)$ & & \\
Fator 3c & 1 & $3,34(0,56)$ & 94,28 & 0,001 \\
& 2 & $2,76(0,60)$ & & \\
Fator 4c & 1 & $3,47(0,65)$ & 105,20 & 0,001 \\
& 2 & $4,02(0,42)$ & & \\
Fator 1m & 1 & $2,86(0,55)$ & 6,53 & 0,010 \\
& 2 & $2,98(0,42)$ & & \\
Fator 2m & 1 & $2,46(0,67)$ & 0,02 & n.s. \\
& 2 & $2,44(0,80)$ & & \\
Fator 3m & 1 & $3,20(0,86)$ & 21,37 & 0,001 \\
& 2 & $3,53(0,71)$ & & \\
Fator 4m & 1 & $3,03(0,69)$ & 3,25 & n.s. \\
& 2 & $3,13(0,73)$ & & \\
Fator 5m & 1 & $2,41(0,82)$ & 1,27 & n.s. \\
& 2 & $2,48(0,72)$ & & \\
Fator 6m & 1 & $3,37(1,00)$ & 5,29 & 0,05 \\
& 2 & $3,60(0,85)$ & & \\
\hline
\end{tabular}

Notas: Escola 1 - Pública; Escola 2 - Particular. n.s. - não significativo. fatores de criatividade e motivação e variáveis independentes gênero e tipo de escola, não demonstraram diferenças significativas entre os fatores e gênero, mas demonstraram a existência de diferenças significativas entre os fatores de criatividade e tipo de escola e entre três fatores de motivação e tipo de escola (Wilks Lambda $=0,61 ; p<0,001$ ). Foram encontrados ainda efeitos de interação de tipo de escola e gênero (Wilks Lambda $=0,92 ; p<0,001$ ) nos fatores Jogos e Desafios e Resolução de Problemas da Escala de Motivação em Matemática.

Assim, foram encontradas diferenças significativas entre todos os fatores do Inventário de Práticas Docentes para a Criatividade e tipo de escola e entre os fatores 1 (Satisfação pela Matemática), 3 (Resolução de Problemas) e 6 (Interações na Aula de Matemática) da Escala de Motivação em Matemática e tipo de escola (ver Tabela 1).

Como pode ser observado nessa tabela, médias significativamente superiores foram obtidas pelos alunos de escola particular comparativamente aos de escola pública nos seguintes fatores do Inventário de Práticas Docentes: Incentivo a Novas Ideias ( $F[1,393]=90,62 ; p=0,0001)$, Clima para Expressão de Ideias $(F[1,393]=121,10 ; p=0,0001)$ e Interesse pela Aprendizagem do Aluno ( $F[1,393]=105,20$; $p=0,0001)$. Dessa forma, pode-se afirmar que os alunos da escola particular avaliaram mais positivamente seus professores em relação a incentivar o desenvolvimento de novas ideias, propiciar clima em sala de aula para a expressão de ideias e mostrar interesse pela aprendizagem do aluno. Por outro lado, a média dos alunos de escola pública $(M=3,34)$ foi significativamente superior à dos alunos de escola particular ( $M=2,76)$ no fator Avaliação e Metodologia de Ensino $(F[1,393]=94,28 ; p=0,0001)$, sinalizando que os alunos da escola pública percebiam seus professores mais orientados para a avaliação e utilização de metodologias de ensino tradicionais.

Em relação aos fatores da Escala de Motivação em Matemática, foram obtidas médias significativamente superiores pelos alunos de escolas particulares, comparativamente aos de escola pública, nos fatores Satisfação pela Matemática $(F[1,393]=6,53 ; p=0,011)$, Resolução de Problemas $(F[1,393]=21,37 ; p=0,0001)$ e Interações na aula de Matemática $(F[1,393]=5,29 ; p=0,022)$. Desta análise apreende-se que os alunos da escola particular expressaram gostar mais de Matemática, de resolver problemas de Matemática e tinham melhores interações com colegas e professor na aula dessa disciplina que os alunos da escola pública.

Além disso, os resultados obtidos revelaram haver interação significativa entre gênero e tipo de escola em relação ao fator 2 (Jogos e Desafios) $(F[1,393]=8,06 ; p=0,005)$ e 3 (Resolução de Problemas) $(F[1,393]=5,62 ; p=0,018)$ da Escala de Motivação em Matemática. Na escola particular, os alunos do gênero masculino avaliaram mais positivamente o fator Jogos e Desafios ( $M=2,60$; $D P=0,81)$ quando comparados às alunas do gênero feminino $(M=2,31$; $D P=0,78)$, demonstrando haver maior discrepância entre os gêneros na escola particular em relação a Jogos e Desafios. Obser- 
vou-se ainda que as alunas do gênero feminino de escola pública $(M=2,51$; $D P=0,69)$ apresentaram avaliação mais positiva em Jogos e Desafios em relação às suas colegas do mesmo gênero de escolas particulares, e os alunos do gênero masculino da escola particular apresentaram média maior em relação aos da escola pública $(M=2,39 ; D P=0,64)$ (ver Figura 1).

Figura 1. Efeito de interação entre gênero e tipo de escola no fator Jogos e Desafios.

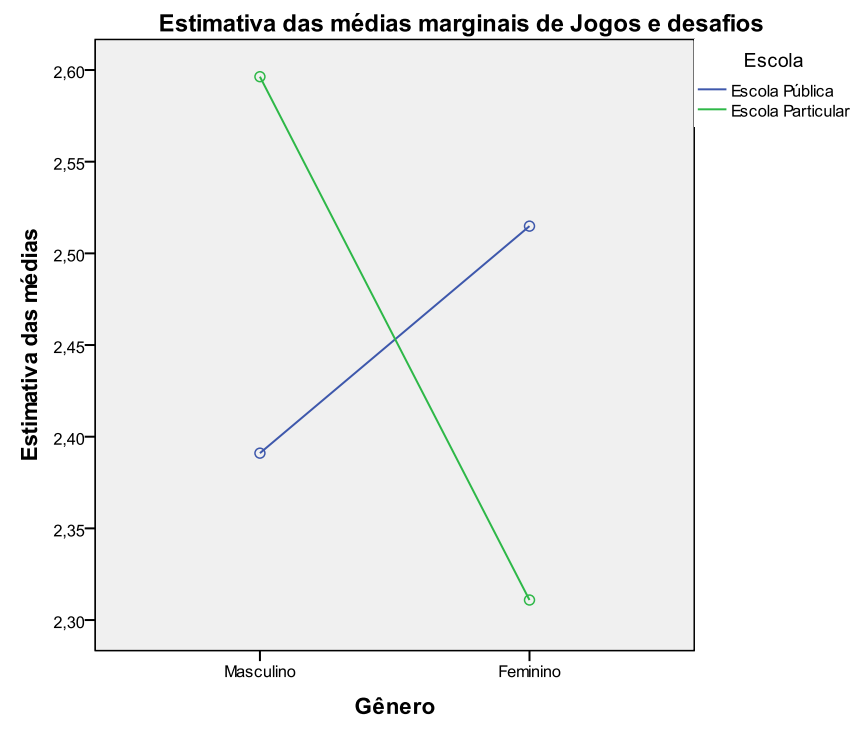

Ademais, os alunos do gênero masculino de escola particular avaliaram mais positivamente o fator Resolução de Problemas da Escala de Motivação $(M=3,62$; $D P=0,68)$ quando comparados aos do mesmo gênero de escola pública $(M=3,10 ; D P=0,83)$. Mas essa relação não pode ser observada entre as alunas do gênero feminino de escola pública $(M=3,28 ; D P=0,87)$ e de escola particular $(M=3,46$; $\mathrm{DP}=0,73)$. Assim, os alunos do gênero masculino da escola particular informaram gostar mais de resolver problemas de Matemática que os alunos desse mesmo gênero da escola pública (ver Figura 2).

\section{Relações entre percepção de práticas docentes para a criatividade, motivação em Matemática e desempenho acadêmico nessa disciplina}

Na Tabela 2, é apresentado o valor das correlações entre os fatores do Inventário de Práticas Docentes para a Criatividade e Motivação Geral em Matemática. Os índices apontaram correlações positivas entre Motivação Geral e Incentivo a Novas Ideias $(r=0,37 ; p=0,0001)$, Clima para Expressão de Ideias $(r=0,26 ; p=0,0001)$ e Interesse pela Aprendizagem do Aluno $(r=0,36 ; p=0,0001)$. Isso indica que, quanto mais positiva a percepção pelos alunos do uso por seu professor de Matemática de práticas pedagógicas relativas a incentivo ao desenvolvimento de novas ideias
Figura 2. Efeito de interação entre gênero e tipo de escola no fator Resolução de Problemas.

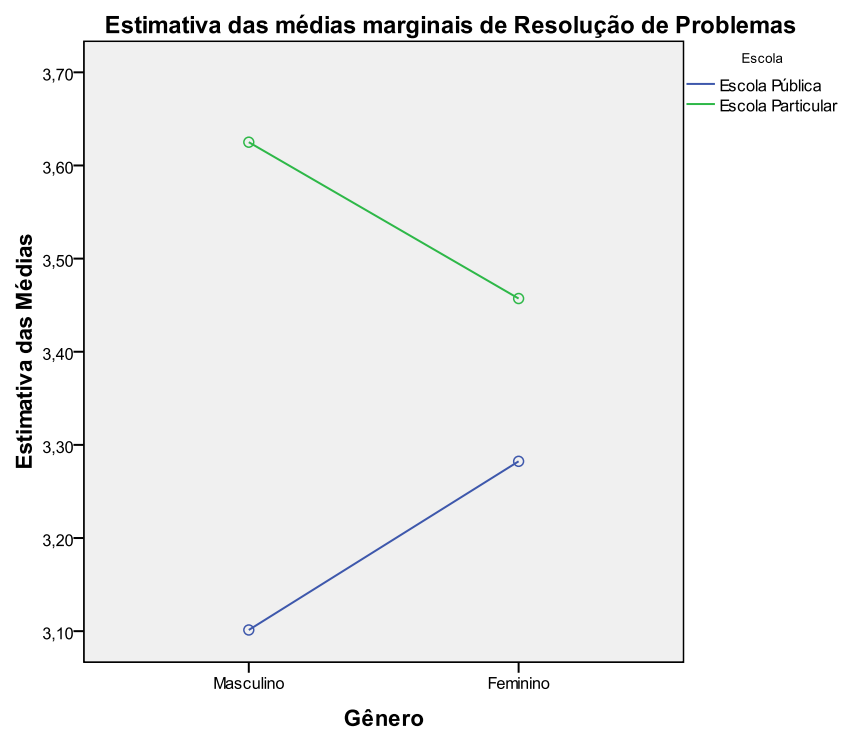

Tabela 2. Correlações entre os Fatores do Inventário de Práticas Docentes para a Criatividade e Motivação Geral em Matemática.

\begin{tabular}{lcc}
\hline \multicolumn{3}{c}{ MOTIVAÇÃO GERAL } \\
\hline FATORES & $\mathbf{r}$ & $\mathbf{p}$ \\
\hline Incentivo a Novas Ideias & 0,37 & 0,0001 \\
Clima para Expressão de Ideias & 0,26 & 0,0001 \\
Avaliação e Metodologia de Ensino & $-0,16$ & 0,002 \\
Interesse pela Aprendizagem do Aluno & 0,36 & 0,0001 \\
\hline
\end{tabular}

e manutenção de clima positivo para expressão de ideias, maior é a sua motivação por Matemática.

Observou-se também uma correlação negativa, embora baixa, significativa $(r=-0,16 ; p=0,002)$ entre Motivação Geral e o fator Avaliação e Metodologia de Ensino. Isso denota uma tendência a uma menor motivação em Matemática por parte dos alunos que consideraram que o seu professor utiliza procedimentos docentes típicos do método tradicional de ensino, como uso de formas de avaliação que exigem do aluno apenas a reprodução de conteúdo, poucas oportunidades de escolha com relação aos trabalhos a serem desenvolvidos e mesma metodologia de ensino utilizada em todas as aulas.

Os resultados também indicaram correlações positivas significativas entre a nota em Matemática e os fatores de Motivação em Matemática. Observaram-se as seguintes correlações entre nota e Matemática e: 1) Satisfação pela Matemática $(r=0,32 ; p=0,0001) ; 2)$ Jogos e Desafios $(r=$ $0,21 ; p=0,0001) ; 3$ ) Resolução de Problemas $(r=0,30 ; p$ $=0,0001)$; 4) Aplicações no Cotidiano $(r=0,16 ; p=0,002)$; 5) Interações na Aula de Matemática $(r=0,15 ; p=0,002)$; e 6) Motivação Geral ( $r=0,31 ; p=0,0001)$, denotando que, 
Tabela 3. Correlação entre Rendimento Acadêmico e Fatores da Escala de Motivação em Matemática.

\begin{tabular}{lcc}
\hline & FATOR & NOTA \\
& $\mathbf{r}$ & $\mathbf{p}$ \\
\hline Satisfação pela Matemática & 0,32 & 0,0001 \\
Jogos e Desafios & 0,21 & 0,0001 \\
Resolução de Problemas & 0,30 & 0,0001 \\
Aplicações no Cotidiano & 0,16 & 0,002 \\
Hábitos de Estudo & 0,08 & n.s. \\
Interações na Aula de Matemática & 0,15 & 0,002 \\
Motivação Geral & 0,31 & 0,0001 \\
\hline
\end{tabular}

quanto maior a motivação em Matemática, melhor é o rendimento acadêmico do aluno nessa disciplina. Entretanto, algumas das correlações significativas tiveram valor pouco expressivo e possivelmente mostraram-se significativas em função do tamanho da amostra. Isso ocorreu nos fatores Aplicações no Cotidiano e Interações na Aula de Matemática (ver Tabela 3).

Da mesma forma, verificaram-se correlações positivas entre os fatores do Inventário de Práticas Docentes para a Criatividade Incentivo a Novas Ideias, Clima para Expressão de Ideias e Interesse pela Aprendizagem do Aluno e a nota em Matemática. Por outro lado, encontrou-se correlação negativa entre Avaliação e Metodologia de Ensino e a nota nessa disciplina (ver Tabela 4).

Tabela 4. Correlação entre Rendimento Acadêmico e Fatores do Inventário de Práticas Docentes para a Criatividade

\section{RENDIMENTO ACADÊMICO}

\begin{tabular}{lcc}
\hline \multicolumn{1}{c}{ FATORES } & $\mathbf{r}$ & $\mathbf{p}$ \\
\hline Incentivo a Novas Ideias & 0,22 & 0,001 \\
Clima para Expressão de Ideias & 0,16 & 0,010 \\
Avaliação e Metodologia de Ensino & $-0,27$ & 0,001 \\
Interesse pela Aprendizagem do Aluno & 0,25 & 0,001 \\
\hline
\end{tabular}

\section{Discussão}

Observou-se, na presente pesquisa, que os estudantes da instituição particular apresentaram uma percepção mais positiva de práticas pedagógicas promotoras da criati- vidade por parte de seu professor de Matemática, comparativamente aos estudantes de escola pública. Vários fatores podem ser apontados para explicar tal resultado. Um deles refere-se à diversidade de recursos para uso em sala de aula, disponíveis ao docente da instituição particular onde os dados foram coletados, tais como computadores e programas educacionais. Ademais, a escola tem como um dos objetivos de sua proposta pedagógica o desenvolvimento da criatividade do aluno, conta com um coordenador de área e ainda promove reuniões dos docentes para planejamento das atividades a serem desenvolvidas no decorrer do bimestre. Possivelmente, tais condições contribuem para uma prática promotora da criatividade, o que foi percebido pelos participantes desta pesquisa, que estudaram em escola particular.

Observou-se que, apenas no fator Avaliação e Metodologia de Ensino do Inventário de Práticas Docentes para a Criatividade, foram os alunos da escola pública os que obtiveram média significativamente superior, quando comparados aos estudantes da instituição particular. Dado o conteúdo dos itens contidos nesse fator, por exemplo, uso de formas de avaliação que exigem apenas reprodução do conteúdo dado em classe ou contido nos livros-texto, poucas opções de escolha com relação aos trabalhos a serem desenvolvidos e metodologia de ensino que se repete em cada aula, pode-se inferir condições menos propícias ao desenvolvimento e expressão da criatividade.

Os resultados também apontaram que, ao se comparar estudantes de instituições pública e particular quanto à motivação em Matemática, médias significativamente superiores foram obtidas pelos alunos da escola particular nos fatores Satisfação em Matemática, Resolução de Problemas e Interações na Aula de Matemática e Motivação Geral. Tais resultados estão em consonância com os de Marchiore e Alencar (2009), que investigaram a percepção de estudantes do Ensino Médio acerca de sua motivação para aprender, uma vez que também essas pesquisadoras constataram diferenças significativas em favor dos alunos da escola particular na motivação para aprender. Nota-se que alguns itens do fator Resolução de Problemas, como "tento resolver um mesmo problema matemático de maneiras diferentes", "diante de um problema, sinto muita curiosidade em saber sua resolução", "quando minhas tentativas de resolver um problema fracassam, tento de novo", traduzem um maior nível de motivação intrínseca. Esta tem sido apontada pela literatura (Bzuneck, 2004, 2010; Boruchovitch, 2004; Guimarães, 2004) como a que mais contribui para a aprendizagem do aluno. Por outro lado, os itens do fator Interações na Aula de Matemática, como "faço perguntas nas aulas de Matemática quando eu tenho dúvidas" e "me relaciono bem com o meu professor de Matemática", caracterizam também um clima propício à expressão da criatividade, conforme sinalizado anteriormente por Alencar e Fleith (2009). Ademais, Alencar (2000), em estudo sobre as características do professor facilitador e daquele que inibe a criatividade discente, constatou o incentivo ao aluno para fazer perguntas sobre os tópicos abordados em aula e relacionamento amigável 
professor-aluno como atributos apontados no professor facilitador da criatividade. Pelos resultados obtidos, pode-se supor que o professor da escola particular não apenas propiciava melhores condições ao desenvolvimento do potencial criador, mas era também mais motivado pela atividade de ensino do que o da escola pública. Em relação a esse aspecto, Tapia e Fita (2006) consideram que, se o professor não estiver motivado, se não exercer de forma satisfatória a sua profissão, muito dificilmente será capaz de transmitir a seus alunos entusiasmo e interesse pelas tarefas escolares.

Pode-se também levantar a hipótese de que os alunos da escola particular sejam mais motivados intrinsecamente. Esse tipo de motivação caracteriza indivíduos que se engajam em uma atividade por iniciativa própria, por achá-la interessante ou prazerosa. Guimarães (2004) destaca que, quando o aluno apresenta predominância de motivação intrínseca, mostra-se mais curioso, interessado, atento, concentrado e persistente no desempenho das mais variadas atividades.

Não foram encontradas, no presente estudo, diferenças significativas entre gênero tanto nos fatores avaliados pelo Inventário de Práticas Docentes para a Criatividade como na Escala de Motivação em Matemática. É notório que há uma vasta literatura chamando a atenção para as diferenças de gênero, a favor do gênero masculino, em desempenho em Matemática e motivação em relação a esta disciplina (Fox, Engle, \& Paeck, 2001; Heller \& Ziegler, 2010; Preckel, Goetz, Pekrun, \& Kleine, 2008). Ademais, no Brasil, Gontijo e Fleith (2009) encontraram médias significativamente superiores, por parte dos estudantes do gênero masculino, nos fatores Jogos e Desafios e Resolução de Problemas da Escala de Motivação em Matemática.

Os resultados apontaram relação positiva entre a percepção dos alunos quanto ao uso de estratégias em sala de aula para desenvolver a criatividade pelos professores e a motivação dos alunos em Matemática. Tal resultado vem ao encontro do apontado por Fleith e Alencar (2010), em texto a respeito das relações entre criatividade e motivação. As autoras sinalizam que, entre os elementos do contexto educacional que têm influência tanto na expressão da criatividade como na motivação do aluno, estão os procedimentos dos docentes em sala de aula e que métodos de ensino centrados no professor são fatores que contribuem para reduzir a motivação do aluno para aprender e a expressão do seu potencial para criar.

Em complemento, Bzuneck $(2004,2010)$ ressalta que o professor em classe deve prevenir a ocorrência de condições negativas, como o tédio crônico, a apatia ou a alta ansiedade e, mais do que tudo, deve desenvolver e manter a motivação positiva da classe como um todo, série após série, pois a motivação do aluno em sala de aula resulta de um conjunto de medidas educacionais, que incluem certas estratégias de ensino ou eventos, sobre os quais todo professor tem amplo poder de decisão. Assim, o novo desafio para os educadores é ser criativo na preparação e na execução das aulas. Hoje, o professor deve ter a habilidade de articular, liderar, convencer e desenvolver talentos nos alunos para a efetivação de um ensino de qualidade (Kauark \& Muniz, 2008).

Demo (1993) lembra que o professor deve ser capaz de desenvolver no estudante a capacidade de raciocínio, de posicionamento, tornando-o desafiador, provocador e instigador. Mas, para tanto, é necessário que o docente aprenda a ler criticamente; obtenha redação própria e expresse-se com desenvoltura; domine conhecimentos e informações estratégicas do processo de transformação da realidade atual; pesquise, iniciando com pequenas investigações e, posteriormente, passando para elaborações mais exigentes, que já expressem capacidade de síntese, de compreensão global, de posicionamento crítico e criativo; aprimore habilidade metodológica para manejar e produzir conhecimento.

Diante das frequentes dificuldades para aprender Matemática, o papel do professor é fundamental. Cabe a ele não apenas auxiliar o aluno a dominar os conteúdos dessa disciplina, como também motivá-los, levando-os a ter prazer em estudar e aprender Matemática. Segundo D’Ambrósio (2007), é importante que o professor de Matemática tenha visão do que vem a ser a Matemática, do que constitui a atividade matemática e do que caracteriza um ambiente propício à aprendizagem da Matemática. Isso, paralelamente ao uso de estratégias de ensino promotoras da criatividade, possivelmente contribuiria para assegurar níveis mais altos de motivação para aprender Matemática pelos alunos.

Embora o presente estudo tenha limitações, como, por exemplo, dados coletados em alunos de uma única série do Ensino Médio e de uma única escola pública e outra particular, os seus resultados podem ajudar pesquisadores e educadores a compreender melhor a relação entre práticas pedagógicas utilizadas pelo professor e motivação do aluno e ainda a relação entre motivação do aluno e seu rendimento acadêmico em Matemática. Oferece ainda algumas sugestões de como melhorar a educação matemática, o que é de extrema importância no país, dados os baixos índices de proficiência nesta disciplina, expressos, por exemplo, em testes oficiais, como o Sistema de Avaliação Básica - SAEB.

\section{Referências}

Alencar, E. M. L. S. (2000). O perfil do professor facilitador e do professor inibidor da criatividade segundo estudantes de pósgraduação. Boletim da Academia Paulista de Psicologia, 19, 8494.

Alencar, E. M. L. S. (2002). O estímulo à criatividade em programas de pós-graduação segundo seus estudantes. Psicologia: reflexão e crítica, 15, 63-70.

Alencar, E. M. L. S. (2007). O papel da escola na estimulação do talento criativo. Em D. S. Fleith \& E. M. L. S. Alencar (Orgs.), Desenvolvimento de talentos e altas habilidades: Orientação a pais e professores (pp. 151-162). Porto Alegre: ArtMed.

Alencar, E. M. L. S., \& Fleith, D. S. (2004). Inventário de Práticas 
Docentes que Favorecem a Criatividade no Ensino Superior. Psicologia: reflexão e crítica, 17, 105-110.

Alencar, E. M. L. S., \& Fleith, D. S. (2009). Criatividade: múltiplas perspectivas (3a ed.). Brasília: Ed. UnB.

Bzuneck, J. A. (2004). A motivação do aluno: aspectos introdutórios. Em E. Boruchovitch \& J. A. Bzuneck (Orgs.), A motivação do aluno: contribuições da Psicologia Contemporânea (pp. 9-36). Petrópolis, RJ: Vozes.

Bzuneck, J. A. (2010). Como motivar os alunos: sugestões práticas. Em E. Boruchovitch, J. A. Bzuneck \& S. E. R. Guimarães (Orgs.), Motivação para aprender (pp. 13-42). Petrópolis, RJ: Vozes.

Boruchovitch, E. (2004). Inteligência e motivação: perspectivas atuais. Em E. Boruchovitch \& J. A. Bzuneck (Orgs.), A motivação do aluno: contribuições da Psicologia Contemporânea (pp. 96115). Petrópolis, RJ: Vozes.

Cunha, M. I. (2006). O bom professor e sua prática (18a ed.). São Paulo: Papirus.

D’Ambrósio, B. S. (1989). Como ensinar matemática hoje? Temas e debates, 2, 15-19.

D`Ambrósio, U. (2007). Educação matemática da teoria à prática (15a ed.). São Paulo: Papirus.

Demo, P. (1993). Desafios modernos da educação. Petrópolis, RJ: Vozes.

Fleith, D. S. (2007). Como desenvolver a criatividade no contexto educacional. Em SESI - Departamento Nacional (Org.), Criatividade (pp. 9-30). Brasília: SESI - Departamento Nacional.

Fleith, D. S., \& Alencar, E. M. L. S. (2010). A inter-relação entre criatividade e motivação. Em E. Boruchovitch, J. A. Bzuneck \& S. E. R. Guimarães (Orgs.), Motivação para aprender (pp. 209-230). Petrópolis, RJ: Vozes.

Fox, L. H., Engle, J. L., \& Paeck, P. (2001). An exploratory study of social factors and Mathematics achievement among high-scoring students: Cross-cultural perspectives from TIMSS. Gifted and Talent International, 16, 7-15.

Gontijo, C. H. (2007). Relações entre criatividade, criatividade em Matemática e motivação em Matemática de alunos do ensino médio. Tese de Doutorado, Universidade de Brasília, Brasília.

Gontijo, C. H., \& Fleith, D. S. (2009). Motivação e criatividade em Matemática: um estudo comparativo entre alunas e alunos de ensino médio. ETD. Educação Temática Digital, 10, 147-167.

Guimarães, S. E. R. (2004). Motivação intrínseca, extrínseca e o uso de recompensas em sala de aula. Em E. Boruchovitch \&
J. A. Bzuneck (Orgs.), A motivação do aluno: contribuições da Psicologia contemporânea (pp. 78-95). Petrópolis, RJ: Vozes.

Heller, K. A., \& Ziegler, A. (2010). Gender differences in Mathematics and the Natural Sciences. Em K. A. Heller (Org.), Munich studies of giftedness (pp. 219-238). Berlin: LIT.

Kauart, F., \& Muniz, I. (2008). Motivação no ensino e na aprendizagem: competências e criatividade na prática pedagógica. Rio de Janeiro: Wak.

La Torre, S. (2005). Dialogando com a criatividade: da identificação à criatividade paradoxal. São Paulo: Madras.

Libâneo, J. C. (1994). Didática. São Paulo: Cortez.

Lubart, T.(2007). Psicologia da criatividade. Porto Alegre: Artmed.

Marchiore, L. W. O., \& Alencar, E. M. L. S. (2009). Motivação para aprender em alunos do ensino médio. ETD. Educação Temática Digital, 10, 105-123.

Martínez, A. M. (2002). A criatividade na escola: três direções de trabalho. Linhas críticas, 8,189-206.

Martínez, A. M. (2006). Criatividade no trabalho pedagógico e criatividade na aprendizagem. Uma relação necessária? Em M. C. V. R. Tacca (Org.), Aprendizagem e trabalho pedagógico (pp. 69-94). Campinas, SP: Alínea.

Pais, L. C. (2006). Ensinar e aprender Matemática. Belo Horizonte: Autêntica.

Preckel, F., Goetz, T., Pekrun, R., \& Kleine, M. (2008). Gender differences in gifted and average-ability students: Comparing girl's and boy's achievement, self-concept, interest, and motivation in Mathematics. Gifted Child Quarterly, 52(2), 146-159.

Sequera Guerra, E. C. (2006). Creatividad em educación matemática. Em S. de la Torre \& V. Violant (Orgs.), Comprender y evaluar la creatividad (pp. 475-470). Málaga: Aljibe.

Silveira, M. R. A (2002). Matemática é difícil. Em Reunião Anual da Associação Nacional de Pesquisa e Pós-Graduação em Educação. Caxambu. Anais. Caxambu: Anped. Recuperado: 24 out. 2008. Disponível: <www.anped.org.br/25/marisarosaniabreusilveirat19. $\mathrm{rtf}>$.

Tabachnick, B. G., \& Fidel, L. S. (1996). Using multivariate statistics. Nova lorque: Harper Collins.

Tapia, J. A. (2003). Motivação e aprendizagem no ensino médio. Em C. Coll, C. Gotzens, C. Monereo \& J. Onrubia, J. (Orgs.), Psicologia da aprendizagem no ensino médio (pp. 103-140). Porto Alegre: Artmed. 
Tapia, J. A., \& Fita, E. C. (2006). A motivação em sala de aula: o que é, como se faz. São Paulo: Loyola.
Wechsler, S. M. (1998). Criatividade: descobrindo e encorajando - contribuições teóricas e práticas para as diversas áreas. São Paulo: Editora Psy.

Zaslavsky, C. (2009). Criatividade e confiança em Matemática. Porto Alegre: Artmed.

Recebido em: 03/03/2011

Reformulado em: 20/12/2011

Aprovado em: 24/01/2012

\section{Sobre a autora}

Profa. Dra. Eunice M. L. Soriano de Alencar (ealencar@pos.ucb.br)

Programa de Pós-Graduação em Educação - Universidade Católica de Brasília - SGAN 916 Módulo B Asa Norte - 70790-160 Brasília, DF.

Este trabalho é derivado da Dissertação de Mestrado defendida pela primeira autora, sob a orientação da segunda, no Programa de PósGraduação em Educação da Universidade Católica de Brasília. 


\section{ERRATA}

A Comissão Editorial da Revista Psicologia Escolar e Educacional comunica que no V. 16, n.1 publicou o artigo "Estímulo à Criatividade por Professores de Matemática e Motivação do Aluno" e foi constatado o seguinte erro:

\begin{tabular}{|c|c|}
\hline Onde & p.61 \\
\hline Onde se lê & $\begin{array}{l}\text { ABSTRACT } \\
\text { In this study we investigate the perception high school students have about the } \\
\text { use of educational practices favorable to creativity and motivation in mathematics } \\
\text { by their teachers. Participants were } 396 \text { students who responded to the Inventory } \\
\text { of Educational Practices for Creativity and Motivation Scale in Mathematics. } \\
\text { Significant differences were observed between students from public and from } \\
\text { private schools in the perception of teaching practices that promote creativity and } \\
\text { motivation in mathematics. Private school children revealed a better perception of } \\
\text { the teacher's use of these instruments. There was significant correlation between } \\
\text { students' perceptions regarding the use of strategies in the classroom to develop } \\
\text { creativity by his mathematics teacher and student motivation in mathematics. } \\
\text { There is also a correlation between motivation and academic performance in } \\
\text { mathematics and between the students' perception of teaching practices for } \\
\text { creativity and their performance in mathematics. } \\
\text { Keywords: Creativity, motivation, Mathematics. }\end{array}$ \\
\hline Leia-se & $\begin{array}{l}\text { ABSTRACT } \\
\text { The study investigated high school students perception about pedagogical } \\
\text { practices used by their Mathematics teacher to promote the development of } \\
\text { creativity and students' motivation in Mathematics. The participants were } 396 \\
\text { students who completed the Inventory of Teaching Practices for Creativity and } \\
\text { the Scale of Motivation in Mathematics. Significant differences were observed } \\
\text { between public and private school students in their perception of pedagogical } \\
\text { practices implemented by the Mathematics teacher to develop creativity and in } \\
\text { their motivation in Mathematics, favoring the private school students. The results } \\
\text { also indicated a relationship between students' perception of the use of strategies } \\
\text { to develop creativity in the classroom by their Mathematics teacher and motivation } \\
\text { in Mathematics, between motivation in Mathematics and academic achievement, } \\
\text { and between student's perception of teaching practices for creativity and } \\
\text { academic achievement in Mathematics. } \\
\text { Keywords: Creativity, motivation, teacher, Mathematics. }\end{array}$ \\
\hline
\end{tabular}

